\title{
İnkontinansa Bağlı Dermatit: Değerlendirme, Önleme ve Tedavi
}

\section{Incontinence Related Dermatitis: Assessment, Prevention and Treatment}

(Derleme)

\author{
Pınar AVŞAR*, Ayişe KARADAĞ**
}

Öz

Üriner ve fekal inkontinas, hastanın fiziksel, sosyal, psikolojik olarak yaşantısını etkileyen ve ekonomik yük getiren önemli bir sağlık sorunudur. İnkontinansın yol açtığı en yaygın deri sorunu inkontinansa bağlı dermatittir. Hemşirelik bakımı ile yakından ilişkili olan inkontinansa bağlı dermatit; deride idrar ve/veya dışkı temasına bağlı olarak gelişen perineal tahriştir. İnkontinans alakalı dermatit, bireyin sağlığını ve yaşam kalitesini etkilemenin yanı sıra para, zaman ve iş gücü kayıplarına yol açar. Sınırlı sayıdaki çalışmada inkontinansa bağlı dermatit prevalansı \%5.6' dan \%50'ye kadar değișen aralıkta verilmiștir. İnkontinansı yönetmek ve yapılandırılmış bir deri bakımı uygulamak, inkontinansa bağlı dermatitin önlenmesinde ve tedavisinde anahtar girişimlerdir. Bu makalede inkontinansa bağlı dermatitin önlenmesi ve tedavisi güncel kanıtlar doğrultusunda ele alınmıştır.

Anahtar Kelimeler: Hemşirelik bakımı, inkontinansa bağlı dermatit, önleme ve tedavi.

\section{ABSTRACT}

Urinary and fecal incontinence is an important health problem that affects physical, social and psychological experience of the patient and brings economic burden. The most common skin problem caused by incontinence is incontinence related dermatitis. Incontinence related dermatitis which is closely related to nursing care is perineal irritation due to contact with urine and/or feces on the skin. Incontinence related dermatitis affects the individual's health and quality of life, as well as leads to loss of money, time and labor. The prevalence of incontinence related dermatitis was ranged from $5.6 \%$ to $50 \%$ in a limited number of studies. Managing incontinence and applying structured skin care are the key initiatives in the prevention and treatment of incontinence related dermatitis. In this article, the prevention and treatment of incontinence related dermatitis was addressed in line with current evidence.

Key Words: Incontinence related dermatitis, nursing care, prevention and treatment.

\footnotetext{
* Ankara Yıldırım Beyazıt Üniversitesi Sağlık Bilimleri Fakültesi Hemşirelik Bölümü, Ankara, Türkiye Tel: 05308782472 E posta: p.avsar.ank@gmail.com ORCID: https://orcid.org/0000-0002-7637-1700 **Koç Üniversitesi Hemşirelik Fakültesi Hemşirelik Esaslari Anabilim Dalı, İstanbul, Türkiye Telefon: 05356214078 E-mail: ayisekaradag@gmail.com ORCID: https://orcid.org/0000-0001-6436-1647 Geliş Tarihi: 03 Temmuz 2017 Kabul Tarihi: 27 Kasım 2017
} 


\section{GiRiş}

İnkontinansın yol açtığ 1 en yaygın deri sorunu inkontinansa bağlı dermatit (İBD)'dir. Hemşirelik bakımı açısından önemli bir sağlık problemi olan IBD, idrar dışkı ya da her ikisi ile temas nedeniyle perineal deride tahriş olarak tanımlanmaktadır'. İBD, bireylerde önemli ölçüde rahatsızlığa neden olmasının yanı sıra tedavisi zor, zaman alıcı ve pahalıdır ${ }^{1-2}$.

Bebek bezi/alt bezi döküntüsü, irritan dermatit, 1slak lezyonlar, perineal dermatit, perineal döküntü, bez pişiği gibi farklı isimlerle bilinen İBD, fekal ve/veya üriner inkontinansı olan hastalarda görülen irritan kontakt dermatitin bir türüdür. İBD teriminin tercih edilme sebebi terimin, inkontinans nedeniyle doğrudan idrar ve/veya feçes ile temastan kaynaklanan deri sorunlarını diğer deri hastalıklarından ayırt etmesi, bu durumun sadece perine bölgesini değil daha geniş alanı içermesi ve her yaştan insanı etkilemesidir ${ }^{2}$.

Bale ve arkadaşları 2004 yılında İngiltere'de, iki huzurevinde 115' i kadın (\%70.1) ve 49'u erkek (\%29.9) olmak üzere toplam 164 yaşlı birey üzerinde yaptıkları araştırmada, kadınların \%31'inde $(n=115)$, erkeklerin ise \%23'ünde $(n=49)$ üriner inkontinans görüldüğünü saptamışlardır' Türkiye' de gerçek inkontinans sıklığının saptanması güç olmakla birlikte, yapılan bazı çalışmalarda üriner inkontinans sıklığının \%16.4 ile \% 49.5 arasında değiştiği bildirilmiştir ve fekal inkontinans prevalansı da \%8.9 olarak bulmuştur ${ }^{4-6}$. Bu durumun nedenleri arasında; İBD'nin tanılanmasının ve Evre I ve Evre II Basınç Ülseri (BÜ)'den ayırt edilmesinin zor olması, İBD verilerinin toplanması için uluslararası geçerliliği olan ve kabul edilmiş bir yöntemin bulunmaması, İBD tanısı için kabul edilen klinik kriterlerin yokluğu yer almaktadır ${ }^{2,7-9}$.

İdrarve fekal inkontinans, İBD için ana risk faktörleridir. İBD’nin yaygınlığı, inkontinans ile paralellik göstermektedir ${ }^{10}$. İBD, özellikle yaşlılarda sık görülen bir sorun olmasına rağmen bu durum sıklıkla gözden kaçırılmaktadır ${ }^{11}$. Literatürde İBD prevelansı \%5.6\%50; insidansı \%3,4-\%25 arasında değişmektedir ${ }^{2,9,12-15}$. Bliss ve arkadaşlarının 2006 yılında, lojistik regresyon analizi ile huzur evinde 59558 hastanın hemşirelik kayıtlarını inceledikleri çalışmada; prevelanslar, üriner inkontinans için \%59.8, fekal inkontinans için \%12.4, üriner ve fekal inkontinansın birlikte olduğu durumlarda \%39.7, İBD oranı ise \%5.7 (n:3405) olarak belirlenmiştir ${ }^{12}$. Bliss ve arkadaşlarının 2007 yılında yaptıkları başka bir prospektif çalışmada, huzurevindeki hastaların (n:1918) \%98 (n:1879)'inde inkontinans, \%51 (n:981)'inde İBD belirlenmiştir. Aynı çalışmada ayrıca huzur evleri için İBD’nin oluşma süresinin ortalama 13 gün (min: 6 gün; max: 42 gün) olduğu belirtilmiştir ${ }^{15}$. Arnold-Long 2008 yılında ABD'de uzun süreli akut bakım ünitesinde prospektif olarak yaptığ ${ }_{1}$ çalışmasında 12 hafta süresinde ( $\left.\mathrm{n}=171\right)$, İBD prevalansını \% 22.8; yaklaşık 6.5 gün hastanede yatış süresi içerisinde 10 yeni vaka gelişimi sonucunda İBD insidansını ise \%7.6 olarak rapor etmişlerdir ${ }^{16}$. İBD eski bir olgu olmasına rağmen İBD’ye ilişkin çalışmalar da çok yeni ve az sayıdadır. Ülkemizde Denat ve Khorshid'in fekal inkontinansı kontrol altına almada kullanılan iki farklı ürünün (perianal torba kullanan 15 hasta ve diaper kullanan 15 hasta) perineal dermatit oluşumuna etkisini incelemek amacıyla yapmış oldukları prospektif yarı deneysel çalışmalarında (2011) diaper grubundaki hastaların tümünde, perianal torba grubundaki hastaların ise \%66.7'sinde İBD oluşmuştur ${ }^{17}$. Avşar ve Karadağ'ın müdahale araştırması olarak yoğun bakım ünitelerinde doku toleransını artırmaya yönelik hemşirelik girişimlerinin doku bütünlüğüne olan etkisini inceledikleri çalışmalarında ise (2016) İBD oranları 
kontrol grubunda \%31.2 olarak bulunmuşken, kanıta dayalı hemşirelik girişimlerinin uygulandığı müdahale grubunda bu oran \%10.4 olarak saptanmıştır ${ }^{18}$.

İBD hemşirelik bakımının kalite göstergesi olarak ele alınan BÜ gelişmesine yol açan ana risk faktörlerinden biri olarak beliritilmektedir ${ }^{2,7-8}$. Junkin ve arkadaşlarının 2005 yılında ABD'de üç tıp merkezinin yoğun bakımları dahil olmak üzere, yetişkin akut bakım hastalarında yaptıkları bir pilot çalışmada, 24 saatlik zaman içerisinde üriner, fekal ve miks inkontinansın birlikte olduğu hastalarda ( $\mathrm{n}=198), \mathrm{BÜ} \% 33$, İBD \% 27 ve mantar enfeksiyonu \%18 olmak üzere toplam \%54 $(n=106)$ oranında perineal bölgede cilt hasarı rapor edilmiştiri ${ }^{19}$.

Sağlık bakım hizmetlerinin maliyetini artıran bir sorun olmasına rağmen İBD’nin gerçek maliyetini tahmin etmek güçtür. Çünkü ilgili maliyetleri BÜ’nin önlenmesine ve tedavisine yönelik maliyetlerden ayırt etmek kolay değildir. İBD’nin önlenmeside ve tedavisindeki maliyetin büyük bir kısmı bakım zamanı ile ilișkilidir. Mali analizler; çarşaf değiștirmenin maliyeti, çamaşırhane maliyetlerinin yanı sıra, önlük, eldiven, deri temizleyiciler ve koruyucular gibi alt kalemlerden oluşmaktadır ${ }^{2,15}$. Bliss ve arkadaşlarının bildirdiğine göre (2007), Amerika Birleşik Devletleri için uzun dönem bakım veren kurumlarda İBD’nin maliyeti 136,3 milyon dolardır ${ }^{15}$. Zehrer ve arkadaşları (2005) bir yaşlı bakım evinde, 16 hasta ile yaptıkları çalışmada, bariyer etkili ürünlerin her inkontinans durumundan sonra kullanılmasının günlük maliyetini 0.17 \$- 0.76 \$ arasında belirlemişlerdir ${ }^{19}$. Franz ve arkadaşlarının (2003), 46 hasta ile yaptıkları çalışmada ise bariyer krem ve hemşire iş gücü maliyeti günlük ortalama $2.93 \$$ olarak hesaplanmıştır ${ }^{21}$.

İBD’nin Türkiye'deki durumunu yansıtan kapsamlı bir araştırma sonucuna ulaşılmamakla birlikte gerek gelişmiş ülkelerdeki rakamlar gerekse ortalama yaşam süresinin uzamasına bağlı yaşlı ve her yıl trafik kazaları nedeniyle artan yüksek riskli hasta (hareketlilikte bozulma, bilişsel farkındalığın azalması, felçli hastalar) sayısı dikkate alındığında ülkemiz için de önemli bir sorun olduğunu söyleyenebilir. İBD’nin azaltılması, BÜ ve bununla ilişkili maliyetleri de potansiyel olarak azaltabilir. Bu durum, İBD’nin önlenmesini ve erken tedavisini önemli kılmaktadır.

\section{İnkontinansa Bağlı Dermatitin Değerlendirilmesi}

İBD’nin önlenmesi ve bakımın yönlendirilmesinde, İBD’ye yol açan risk faktörlerinin bilinmesi ve İBD’nin değerlendirilmesi önemli bir yere sahiptir. İBD’nin değerlendirilmesi ve risk faktörlerinin bilinmesi bu tür bakım gereksinimi olan hastalara bu bakımın daha iyi bakım verilmesine olanak sağlar. İBD gelişiminde rol oynayan risk faktörlerinin tam olarak anlaşılabilmesi açısından İBD fizyopatolojisinin bilinmesi önemlidir. Derinin aşırı hidrasyonu ve pH'daki artış İBD' de etkili olan anahtar mekanizmalar olarak belirtilmektedir ${ }^{1,2,22,23}$. İnkontinans durumunda idrar ve/veya feçesten korneositlerin içine su çekilir ve su burada tutulur. Bu aşırı hidrasyon, şişliğe ve stratum korneumun yapısının bozulmasına ve deride gözle görülür değişikliklere (Örn. maserasyon) yol açar. Aşırı hidrasyonun sonucu olarak, irritanlar daha kolaylıkla stratum korneuma nüfuz eder ve enflamasyonun alevlenmesine yol açar. Derinin aşırı hidrasyonu epidermisin; giysiler, inkontinans petleri veya yatak çarşafı ile temasına bağlı sürtünmeden kaynaklanan yaralanma riskini artırır ${ }^{1,2}$.

Derinin normal pH değeri, ortalama 4-6 arasında olup asidiktir. İdrar ve/veya feçese maruz kalan deri, daha alkali hale gelir. Bunun nedeni, derideki bakterilerin üreyi alkali olan amonyağa dönüștürmesidir. Deri pH’sındaki artış, mikroorganizmaların yerleşmesine 
ve deri enfeksiyonu riskinin arttırmasına yol açar. Feçes ayrıca stratum korneuma zarar verebilecek olan lipolitik ve proteolitik enzimleri içerir. Sıvı feçesin katı feçese kıyasla daha zararlı olduğu bilinmektedir. Çünkü sıvı feçes, çok fazla sindirim enzimi içermektedir. Enzimler ayrıca, üre üzerine etki ederek amonyak üretimine yol açabilir, bu da üriner inkontinansta görülen $\mathrm{pH}$ değerini daha da arttırabilir. Enzimler yüksek pH değerinde daha aktiftir. Bu nedenle deri hasarı riski alkali değişikliklerle birlikte artar. Bu durumda, idrar ve feçesin bir arada bulunduğu miks inkontinans, deri üzerinde, tek başına idrar ya da dışkı inkontinansına kıyasla daha fazla iritan etki oluştururur ${ }^{1,2,21,22}$.

İBD’nin gelişmesinde birçok risk faktörü ve bu faktörler arasındaki etkileşimler rol oynamaktadır. İBD için temel risk faktörleri şunlardır ${ }^{2,24}$;

- İnkontinans tipi

- İnkontinans sıklığ 1

- Kapatıcı (Oklüzif) toplama ürünlerinin kullanımı

- Deri toleransında azalma (Örn. Yaşlanma, steroid kullanımı, diyabet)

- Hareketlilikte bozulma

- Bilinç durumunda değişim

- Kişisel hijyeni sağlayamama

- Ağr1

- Ateş

- İlaçlar (antibiyotikler, immünosupresifler, steroidler, kemoterapötik ajanlar veya metabolitleri)

- Kötü beslenme alışkanlıkları

- Yaşamsal riski olan ve yoğun bakım gerektiren hastalıklar.

İBD gelişimine katkıda bulanan diğer faktörler ise aşağıda verilmiştir ${ }^{1,2,22,24,25}$ :

- İnkontinans ürünlerinin yeterince sık değiştirilmemesi nedeniyle derinin idrar ve feçese uzun süreli maruz kalması,

- Su ve sabunla sik sik deri temizlemenin, korneositlere hasar vermesi, lipitleri gidererek kuruluğu artırması ve sürtünme oluşturması nedeniyle derinin bariyer fonksiyonuna zarar vermesi,

- Agresif temizleme tekniğinin (Örn. normal banyo lifi kullanarak) sürtünme kuvvetini artırması ve deriyi aşındırması olarak sıralanabilir.

İBD’nin doğru değerlendirilmesi temel olarak klinik gözlem ve hasta hikayesine dayanmaktadır. İBD’nin değerlendirmesinde ve tanısında yardımcı olacak teknoloji tam anlamıyla mevcut değildir. Derinin bariyer fonksiyonunu ölçmek için, transepidermal su kaybı (TESK) olarak bilinen, deri yoluyla pasif su kaybı ölçümü kullanılmaktadır. Genel olarak, TESK'deki bir artış derinin koruyucu fonksiyonunun bozulduğunun göstergesidir. Ancak, klinikte TESK ölçümlerinin kullanımı karmaşıktır ve yorumlanması zordur. Tanıya yardımcı olmak üzere bu tekniğin uyarlamaları geliştirilebilmişse de, standart klinik değerlendirmeye kıyasla avantajları tam olarak bilinmemektedir ${ }^{1,2,22}$.

Üriner ve/veya fekal inkontinansı olan hastalarda, İBD belirtileri açısından günde en az bir kez ve inkontinans epizotlarının sayısına bağlı olarak daha sık, sistematik deri değerlendirilmesi yapılmalıdır. Perine, perigenital bölgeler, kalçalar, gluteal kıvrım, 
uyluklar, bel, alt karın ve deri kıvrımları; maserasyon, eritem, lezyonların varlı̆g 1 (veziküller, papüller, püstüller, vb.) erozyon veya soyulma (denudasyon), fungal veya bakteriyel deri enfeksiyonu belirtileri açısından gözlenmelidir ${ }^{1,2,22,24,25}$.

İBD gelişme riski taşıyan bireyleri belirlemek, İBD’ye ilişkin önleyici girişimleri planlamaya katkı sağlar. İBD’nin değerlendirilmesi için faklı ölçüm araçları geliştirilmiştir. $\mathrm{Bu}$ araçlardan bazıları geçerlilik açısından incelenmişse de, günlük uygulamadaki kullanımları, klinik karar verme ve bakımın iyileștirilmesine ilişkin yeterli kanıtların olmaması nedeniyle hala sınırlıdır ${ }^{1,2,22,25}$. İBD değerlendirme araçları risk faktörlerinin belirlenmesini sağlar. Literatürde sınırlı sayıda bulunan bu araçlardan birkaçı aşağıda kısaca açıklanmıştır:

Perirektal Cilt Değerlendirme Aracı [Perirectal SkinAssessment Tool (PSA)]: Brown ve Sears tarafından, 1993 yılında, kanser tedavisi alan hastalarda perirektal bölgedeki derinin değerlendirilmesi amacıyla geliştirilmiştir. PSA, deri bütünlügünde bozulma yok, inflamasyonsuz hafif eritem, inflamasyonlu orta derecede eritem, bül veya veziküller ile şiddetli eritem ve ülserasyon olmak üzere beş bölümden oluşmaktadır. $\mathrm{Bu}$ aracın gözlemciler arası güvenirliği $\% 87^{\prime} \mathrm{dir}^{25}$. Araca ilişkin geçerlilik çalışmasının eksikliği ve perirektal bölge ile sınırlı olması gibi eleştiriler mevcuttur ${ }^{1,22}$.

Deri Değerlendirme Aracı [Skin Assessment Tool (SAT)]: Junkin ve Selekof'un bildirdiğine göre (2008); Kenndy ve Lutz tarafından, 1996 yılında geliştirilmiştir. Araç deri bütünlüğünde bozulma, kızarıklık ve erozyon olmak üzere üç kategoriden oluşmaktadır. Her bir kategori için alt puanlamalar mevcuttur. Alt boyutların toplam skoru İBD şiddetinin derecesini belirlemektedir ${ }^{7}$.

İnkontinansa Bağlı Dermatit ve Şiddeti Aracı (The Incontinence- Associated Dermatitis and its Severity Instrument): İBD’nin tanılanması için Borchert, Bliss, Savik ve Radosevich tarafından, 2010 yılında geliştirilmiştir. Uzman görüşü alınarak kapsam geçerliliği yapılmış, güvenirlik için sınıf içi korelasyon kat sayısı 0.98 bulunmuştur. İBD bulunan 13 bölge, kızarıklık, döküntü ve deri kaybı açısından puan verilerek toplam skor hesaplanmaktadır. Olası puan aralığı $0-52$ olarak belirlenmektedir ve iyileşme oldukça toplam puan azalmaktadır ${ }^{27}$. Ülkemizde, Karadağ, Avşar ve Gül tarafından Türkçe dil uyarlaması 2015 yılında yapılmış olup henüz yayınlanmamıştır. Beeckman ve arkadaşları (2015), İBD'nin sınıflanması için, bakımın yönlendirilmesinde deri hasarının düzeyine ve şiddetine dayanan basitleştirilmiş bir yaklaşımın benimsenmesini önermiş ve İBD’nin şiddetini üç bölümde sınıflamışlardır² (Tablo 1).

İBD’yı doğru belirlemek ve basınç ülserlerinden ve kontakt dermatit gibi diğer deri sorunlarından ya da enfeksiyonlara bağlı (Örn. herpes simplex) veya tere bağlı (Örn. intertrigo) lezyonlardan ayırt etmek çoğu zaman zordur. Değerlendirmede, etiyoloji çok önemlidir. Hastanın inkontinansı yoksa, bu durum İBD değildir. İBD’nin doğru değerlendirilmesi ve tanılanması hastanın uygun önleyici bakım ve tedaviyi alması, dokümantasyonun doğru olması, geri ödeme sistemleri için ödemenin kolaylaştırılması açısından önemlidiir ${ }^{1,2,22}$.

\section{İnkontinansa Bağlı Dermatitin Önlenmesi ve Tedavisi}

İnkontinansa bağlı dermatitin önlenmesi ve tedavisi benzerdir ve inkontinansı olan tüm hastaları hedeflemelidir. İnkontinansa bağlı dermatitin önlenmesi ve tedavisinde inkontinansı yönetmek ve yapılandırılmış bir deri bakımı uygulamak anahtar girişimlerdir ${ }^{2}$. 
Tablo 1. İnkontinansa Bağlı Dermatit Sınıflaması

\begin{tabular}{|c|c|}
\hline IBDD Şiddeti & Belirtiler** \\
\hline $\begin{array}{l}\text { Kızarıklık yok ve deri bütünlüğü bozulmamış (risk } \\
\text { altında) }\end{array}$ & $\begin{array}{l}\text { Deri, vücudun geri kalanına kıyasla normaldir } \\
\text { (IBD belirtisi yok) }\end{array}$ \\
\hline Evre 1 - Kızarık* ancak deri sağlam (hafif) & $\begin{array}{l}\text { Eritem } \\
\text { +/- ödem }\end{array}$ \\
\hline Evre 2 - Kızarık* ve deride bozulma var (orta şiddetli) & $\begin{array}{l}\text { Eritem } \\
\text { +/- ödem } \\
\text { +/- veziküller/büller/deri erozyonu } \\
\text { +/- deri denudasyonu } \\
\text { +/- deri enfeksiyonu }\end{array}$ \\
\hline $\begin{array}{l}\text { * Ya da koyu tenli hastalarda daha soluk, daha koyu, } \\
\text { mor, koyu kırmızı veya sarı } \\
\text { ** Hastanın inkontinansı yoksa bu durum İBD değildir. }\end{array}$ & \\
\hline
\end{tabular}

İnkontinans yönetimi, inkontinansın etiyolojisini belirlemek ve kapsamlı bir bakım planı oluşturmak üzere hastanın ayrıntılı değerlendirilmesini gerektirir. Bakım ve tedavi çoğunlukla, beslenme ve sıvı yönetimi veya boşaltım teknikleri gibi invaziv olmayan davranışsal girişimlerle başlar ${ }^{1,2}$. Sandalyeye bağlı hastalar için genel olarak, yetişkin külotları, alt bezleri gibi emici inkontinans yönetim ürünleri tercih edilmelidir. Üriner inkontinans, kalıcı üriner kateter kullanımını gerektirebilir, ancak nozokomiyal enfeksiyon riskinin yüksek olması nedeniyle, bu girişim son seçenek olarak düşünülmelidir ${ }^{2,23}$. Sıvı feçes yönetimi, fekal yönetim sistemi (FYS) ile sağlanabilir. FYS kullanılamıyorsa, bir fekal torba uygulanabilir. Anal sfinktere zarar verme riski nedeniyle, geniş çaplı üriner kateterlerin rektal tüp olarak kullanılması önerilmemektedir ${ }^{2,22,28}$.

Yapılandırılmış bir deri bakımı; deriyi temizleme ve koruma olmak üzere iki anahtar girişimden oluşmaktadır. Ayrıca hastalar deri üzerine sürülen uygun bir deri bakım ürünü kullanılarak derinin bariyer fonksiyonunu destekleyecek ve sürdürecek bir 'onarma' olarak adlandırılan üçünçü bir aşamadan yarar görebilmektedirler².

\section{Deriyi Temizleme}

İBD’ye neden olan idrar ve/veya feces gibi irritanları gidermek amacıyla, deri temizlenmelidir. İnkontinansta kullanılan deri temizleyiciler genelde "perineal deri temizleyiciler" olarak adlandırılırlar. Bu temizleyiciler, losyon veya sıvı çözeltiler şeklinde üretilmiştir. Sıvı temizleyiciler, sprey şişeler içinde ambalajlanmış veya bir beze emdirilmiş formlarda olabilmektedir. Bunun yanında sıvıyı köpüğe dönüştüren bir saklama kabı olarak da ambalajlanabilirler. Birçok deri temizleyici, seyreltilmeden kullanilmalıdir $\mathrm{r}^{2,22,29}$.

Deri temizleyiciler; yüzey gerilimi azaltan, kir ve debrisin deri üzerinde en az kuvvet uygulayarak giderilmesine olanak veren bileşikler (surfaktan) içermektedirler. Kimyasal yapılarına göre çeşitli surfaktan kategorileri bulunmaktadır ve deri temizleyiciler çoğunlukla birden fazla surfaktan içermektedir. Deri temizleyiciler için, yumuşaklıkları nedeniyle iyonik olmayan (yani yüksüz) surfaktanlar (polietilen glikol, alkil poliglikosit, polisorbatlar, oktoksinollar) tercih edilmektedir ${ }^{2,22,29}$. 
İrritanları uzaklaştırmak için derinin temizlenmesi kritik önem taşımaktadır. Geleneksel olarak, inkontinans epizotundan sonra idrar, feçes ve diğer kirleri deriden uzaklaştırmak için standart sabun, su ve normal bir temizleme bezi kullanılır. Ancak, standart sabun alkalidir ve deri pH’sını değiştirerek derinin bariyer fonksiyonuna zarar verdiği gösterilmiştir. Sert dokulu temizleme malzemeleri, sürtünme hasarına neden olarak derinin bariyer fonksiyonunu daha fazla bozabilir. Derinin musluk suyu ile sik yıkanması ise, TESK'deki artışla birlikte derinin bariyer sağlığını olumsuz etkiler. Bu nedenle normal deri pH'sına benzer $\mathrm{pH}$ aralığında olan bir deri temizleyici, geleneksel sabuna tercih edilmelidir. Deri temizleyicilerin bulunmadığ 1 durumlarda, asgari standart olarak yumuşak bir sabun ve su ile temizlik önerilebilmektedir. Birçok deri temizleyici "durulama gerektirmez", uygulama sonrasında da deride kalabilir ve hızlı bir şekilde kuruyarak, elle kurutmanın neden olduğu sürtünmeyi ortadan kaldırır. İnkontinans yönetiminde durulama gerektirmeyen uygun temizleyicilerin kullanılması önerilmektedir ${ }^{2,22,29}$.

İnkontinansta ideal deri temizliği sıklığı kesin değildir. Temizliğin kendisi derinin bariyer fonksiyonunu bozabilir. Bu nedenle inkontinansa bağlı irritanların giderilmesi ile temizliğin neden olduğu irritasyonun önlenmesi veya en aza indirilmesi arasında bir denge sağlanmalıdır².

İBD önlenmesinde ve yönetiminde temizleme ilkeleri şunları içerir:

- Deri, günde en az bir kez ve her fekal inkontinans epizodundan sonra temizlenmelidir.

- Deri, ovalanmadan kaçınarak sürtünmeyi en aza indirecek şekilde nazikçe temizlenmelidir.

- Standart sabunlar kullanılmamalıdır.

- Deri temizliğinde; yumuşak, durulama gerektirmeyen bir sıvı deri temizleyici ya da normal deri pH'sına benzer bir pH’ya sahip, yumuşak, tek kullanımlık, dokuma olmayan bir temizlik mendili kullanılmadır.

- Deri temizledikten sonra gerekirse nazikçe kurulanmalıdır²,9,22,25.

\section{Deriyi Koruma}

İBD’nin önlenmesi için, deriyi temizledikten sonra korumak gerekir. Deri koruyucular, stratum korneum ile nem veya irritanlar arasında bariyer oluşturmak suretiyle İBD’nin önlenmesinde ve tedavisinde kullanılmaktadır. Deri koruyucular'nem bariyerleri'olarak da adlandırılırlar ve içeriklerine bağlı olarak nem ve irritanlara karşı değişken koruma sağlarlar ${ }^{2}$.

Deri koruyucu ürünler krem, macun, losyon ya da film şeklinde formüle edilebilirler. Deri koruyucu ürünlerin ana bileşenleri petrolatum (vazelin), çinko oksit, dimetikon ve akrilat termopolimerdir ${ }^{2}$.

İBD’nin önlenmesi ve tedavisinde deri koruyucu kullanım ilkeleri şöyle sıralanabilir;

- Deri koruyucuyu, deriyi koruma yeteneğine uygun sıklıkta ve üreticinin talimatları doğrultusunda uygulanmalıdır.

- Deri koruyucunun, diğer herhangi bir deri bakım ürünü ile uyumlu olduğundan emin olunmalidir.

- Deri koruyucuyu, idrar ve/veya feçes ile temas eden ya da temas etme olasılığ bulunan tüm deriye uygulanmalıdır $\mathrm{r}^{2,9,22,25}$. 


\section{Deriyi Onarma (Restore)}

Bu aşamada derinin bariyer tabakasının bütünlüğünün korunması ve güçlendirilmesi sağlanır. Derinin onarımı deri üzerinde kalabilen deri bakım ürünleri kullanılarak gerçekleştirilir. "Yumuşatıcılar" olarak bilinen bu ürünler, farklı kimyasal bileşenleri olsa da lipofilik malzeme veya yağlar içerirler. Bu ürünlerle, sağlıklı stratum korneum içinde bulunanlara benzer lipitler (Örn. seramid) ile formüle edilerek, kuruluğun azaltılması ve lipit matriksinin onarılması amaçlanır. Bir diğer bileşen kategorisi ise stratum korneumun içine su çekip burada tutarak işlev gören maddeler olan humektanlardır. Bu ürünlerin yaygın örnekleri arasında, gliserin ve üre sayılabilir ${ }^{2,9,22,25,30}$.

Deriyi onarmak için hastanın derisine uygulanacak herhangi bir ürünün bileşenlerini kontrol ederek, hastanın duyarlı veya alerjik olduğu herhangi bir maddeyi içermediğinden ve inkontinans hastalarında kullanım için uygun olduğundan emin olunmalıdır. Humektanlar, stratum korneum içine su çektikleri için aşırı hidrate olan veya masere deride kullanılmamalıdır ${ }^{2,9,22,25,30}$. Deri bakımında, temizleme, koruma ve onarma için ayrı ürünler kullanılacağı gibi, bu fonksiyonları birleştiren tek bir ürün de seçilebilir. Bu amaçla tasarlanan kontinans bakım mendilleri bulunmaktadır ${ }^{2,9,22,25,30}$. Sonuç olarak, İBD yoğun bakım ve kritik bakım gerektiren birçok hasta grubunda karşılaşılan yaygın, ağrılı ve yıpratıcı bir sorundur ve BÜ gelişimine katkıda bulunur. Ortalama yaşam süresinin uzamasına bağlı toplumlarda yaygın olarak karşılaşılan yaşlılık, artan trafik kazaları İBD görülme sıklığını artırmaktadır. Tüm inkontinans hastaları İBD riski altında olmasından dolayı bireyselleştirilmiş bir önleme planı doğrultusunda İBD’nin değerlendirilmesi, önlenmesi ve tedavi edilmesi gerekmektedir. İBD hemşirelerin mücadele etmesi gereken ve yönetimi konusunda hemşireye büyük sorumlulukların düştüğü önemli bir sağlık problemidir. İBD’nin önleme ve tedaviye ilişkin protokollerinin, klinik uygulama rehberleri ve politikaların geliştirmesi sorunun çözümüne katkıda bulunacaktır.

\section{KAYNAKLAR}

1. Gray M, Bliss DZ, Ermer SJ, Kennedy E, Karen L, Palmer MH. Incontinence associated dermatitis: a consensus. Journal of Wound, Ostomy, and Continence Nursing 2007; 34(1):45-54.

2. Proceedings of the Global İBD Expert Panel. İnkontinansa bağlı Dermatit: Önlemeyi Geliştirme. Wounds International 2015. URL: http://www.woundsinternational.com. 23 Eylül 2016.

3. Bale S, Tebble N, Jones V, Price P. The benefits of implementing a new skin care protocol in nursing homes. J Tissue Viabil 2004;14(2):44-50.

4. Filiz TM, Uludag C, Cinar N, Gorpelioglu S, Topsever P. Risk factors for urinary incontinence in Turkish women. A cross-sectional study. Saudi Med J 2006;27(11):1688-1692.

5. Tozun M, Ayrancı U, Unsal A. Prevelance of urinary incontinence among women and its impact on quality of life in a semirural area of western Turkey. Gynecol Obstet Invest 2009;67(4):241-249.

6. Denat D, Khorshid L. Fekal inkontinansin bakimi ve bakimda kullanilan ürünler. Atatürk Üniversitesi Hemşirelik Yüksekokulu Dergisi 2009;12(2 ):94-103.

7. Junkin J, Selekof JL. Beyond “diaper rash": Incontinence-associated dermatitis: Does it have you seeing RED? Nursing 2008;38(11):56-67.

8. Bliss DZ, Savik K, Thorson MAL, Ehman S, Lebak K, Beilman G. (2011). Incontinence-associated dermatitis in critically ill adults: time to development, severity, and risk factors. Journal Wound Ostomy Continence Nursing 2011;38(4):1-13.

9. Gray M, Beeckman D, Bliss DZ, Donna Z, Fader M, Logan S, et al. Incontinence-associated dermatitis: A comprehensive review and update. Journal Wound Ostomy Continence Nursing 2012;39(1):61-74. 
10. Copson D. Management of tissue excoriation in older patients with urinary or faecal incontinence. Nursing Standard 2006;21(7):57-62.

11. Corcoran E, Woodward S. Incontinence-associated dermatitis in the elderl:treatment options. British Journal of Nursing 2013; 22(8):450-457.

12. Bliss DZ, Savik K, Harms S, Fan Q, Wyman JF. Prevalence and correlates of perineal dermatitis in nursing. Nursing Research 2006;55:243-251.

13. Ehman S, Thorson M, Lebak K, Bliss DZ, Savik K, Thorson MAL. Development of perineal dermatitis in critically ill adults with fecal incontinence. American Journal of Critical Care 2006;15:333-339.

14. Junkin J, Selekof JL. Prevalence of incontinence and associated skin injury in the acute care inpatient. Journal of Wound Ostomy Continence Nursing, 2007;34:260-269.

15. Bliss DZ, Zehrer C, Savik K, Smith G, Hedblom E. An economic evaluation of four skin damage prevention regimens in nursing home residents with incontinence: economics of skin damage prevention. Journal Wound Ostomy Continence Nursing 2007;34:143-152.

16. Arnold-Long.Incontinence-Associated Dermatitis (IAD) in a Long Term Acute care (LTAc) Facility: Findings from a 12 Week Prospective Study. [Abstract] 2011. WOcN National conference, New Orleans LA.

17. Denat Y, Khorshid L. The effect of 2 different care products on incontinence-associated dermatitis in patients with fecal incontinence. Journal of Ostomy Continence Nursing. 2011;38(2):171-176.

18. Avşar P, Karadağ A. Doku Toleransını Artırmaya Yönelik Hemşirelik Girişimlerinin Doku Bütünlüğünün Sürdürülmesine Etkisi ve Maliyet Etkinlik Analizi. Yayınlanmamış Doktora Tezi. 2016. Gazi Üniversitesi Sağlık Bilimleri Enstitüsü, Ankara.

19. Junkin J, Moore-Lisi L, Selekof JL. What we don't know can hurt us. Pilot prevalence survey of incontinence and related perineal skin injury in acute care. [Abstract] 2005. WOcN National conference, Las Vegas NV, June 2005.

20. Zehrer C L, Newman DK, Grove GL, Lutz JB. Assessment of diaper- clogging potential of petrolatum moisture barriers. Ostomy Wound Manage 2005;51:54-58.

21. Frantz RA, Xakellis GC, Harvey PC, Lewis AR. Implementing an incontinence management protocol in long-term care. Clinical outcomes and costs. Journal of Gerontological Nursing 2003;29(8):46-53.

22. Black JM, Gray M, Bliss DZ, Evans KL, Logan S, Baharestani MM, et al. (2011). MASD Part 2: Incontinence-associated dermatitis and intertriginous dermatitis. Journal Wound Ostomy Continence Nursing 2011;38(4):359-70.

23. Langemo D, Hanson D, Hunter S, Thompson P, Oh IE. Incontinence and incontinence associated dermatitis. Advanced Skin Wound Care 2011;24(3):126-140.

24. Shiu SR, Hsu MY, Chang SC, Hui CC, Hsiao HH. Prevalence and predicting factors of incontinenceassociated dermatitis among intensive care patients. Journal of Nursing Healthcare Research 2013;9(3):210-218.

25. Beeckman D, Schoonhoven L, Verhaeghe S, Heyneman A, Defloor T. Prevention and treatment of incontinence-associated dermatitis: literatüre review. Journal of Advance Nursing 2009; 65(6):1141-1154.

26. Brown SD, Sears M. Perineal dermatitis: a conceptual framework. Journal of Ostomy Wound Management 1993; 39(7):20-25.

27. Borchert K, Bliss DZ, Savik K. The Incontinence- Associated Dermatitis and its severity instrument. Journal of Wound, Ostomy and Continence Nursing 2010;37(5):527-535.

28. Morris L. Flexi-Seal ${ }^{\oplus}$ faecal management system for preventing and managing moisture lesions. Wounds United Kingdom 2011;7(2):88-93.

29. Nix DH. Factors to consider when selecting skin cleansing products. Journal Wound Ostomy Continence Nursing 2000;27(5):260-268.

30. MoncrieffG, CorkM,Lawton S, KokietS, Daly C, ClarkC. Use of emollientsin dry-skin conditions:consensus statement. Journal of Clinical \& Experimental Dermatology Research 2013;38:231-38. 